PRESIDENTIAL ADDRESS

\title{
Anaesthesia and Critical Care - past, present and the way forward
}

\author{
Kumudini Ranatunga, MBBS, MD, FRCA \\ President, the College of Anaesthesiologists of Sri Lanka 2012
}

My address today, focuses on "Anaesthesia and Critical Care- past present and the way forward"

As Margret Fairless Barber said "To look backward for a while, is to refresh the eye, to restore it, and to render it more fit for its prime function of looking forward".

\section{Reminiscing the past........}

So, ladies and gentlemen let me try to refresh your memory this evening, by looking back to the past, and mentioning a few landmarks in the history of anaesthesia and critical care in Sri Lanka and the rest of the world. Since much has been talked about the evolution of anaesthesia, I thought of speaking today, on how cardiac anaesthesia and critical care has evolved with time.

Cardiac surgery, anaesthesia and critical care are relatively young specialties, nearly their entire history having occurred during the $20^{\text {th }}$ century.

We have come a long way since the early days, when cardiac anaesthesia and surgery began with mostly "blind" operations being performed, on stenosed heart valves.

A major mile stone in evolution of cardiac surgery and anaesthesia is the invention of hypothermia for surgery. We must be thankful to Dr Bigelo, whose pioneering efforts on use of hypothermia in cardiac surgery revolutionized the cardiac surgical technique. That ultimately paved the way for Dr Lewis to perform the first ever open heart surgery in $1952 .^{1}$

Anaesthesiologists all over the world soon began covering the patients with ice, to reach temperatures of 24-28 degrees Celsius, to reduce the metabolic demands, and to protect the vital organs. The heart was stopped, with cardioplegic solutions containing potassium chloride. This provided a motionless field, for about 30mins, for the surgeon to work. This perfusionless hypothermia held sway, for about two decades, and is still practiced in some centers.

The next major step was the use of "heart lung machine" or cardio-pulmonary by pass machine in 1953. The surgeons could now take their own cool time. Dr John Gibbon, at Jefferson Medical School in Philadelphia, performed the first Atrial Septal Defect closure on CP bypass in 1953. Since then, this technique has been used with great success till 1990s, where we saw the beginnings of "off pump" or "beating heart" surgery, where the heart continues to beat, but stabilized to provide an almost non-moving work surface for the surgeon. Obviously, for such delicate procedures, team work is essential, and the anaesthesiologists play a crucial role in ensuring a successful outcome. ${ }^{2}$

Interestingly enough, the development of intensive care units also, closely followed evolvement of cardiac anaesthesia.

Although it was Florence Nightingale who first practiced grouping critically ill patients together in one area, it was the anaesthesiologist Dr Bjorn Ibsen who established the world's first Intensive Care Unit, for polio victims in Copenhagen in 1953. A year later Dr. Peter Safar, an Austrian anaesthesiologist started the first ICU in the USA. $^{3}$

It is indeed a reason for pride for Sri Lankans, that we did not lag too far behind the developed world; as the first cardiac surgery was performed at the National Hospital, (then called the General Hospital, Colombo) in 1966. The very first Intensive Care Unit was established two years later, in 1968, to care for these cardiac surgical patients post-operatively. ${ }^{4}$ 
Just as cardiac surgery paved the way for Intensive Care in Sri Lanka, the then General Hospital of Ceylon developed into the present National Hospital of Sri Lanka.

The $15^{\text {th }}$ of June 1968 , was a day that created medical history in Sri Lanka, when the first Intensive Care Unit in Sri Lanka was inaugurated. I am very happy that the person instrumental in establishing this Surgical Intensive Care Unit is in this audience today. He is none other than Dr Thistle Jayawardhane, Consultant Cardio-Thoracic Anaesthesiologist, a gentleman par excellence, and a very distinguished Past President of our College. ${ }^{5}$

On a personal note, I consider it an honour to be working today in the very same place where critical care medicine and cardiac anaesthesia originated in Sri Lanka.

The second Intensive Care Unit was started in 1976, as the Recovery Unit in the then General Hospital, Colombo. The third was started in 1980, at the Peradeniya Teaching Hospital. At present, there are more than 85 ICUs around the country managed by Consultant Anaesthetists, as well as a few others, such as paediatric and medical intensive care units, managed by the paediatricians and physicians.

In addition to Dr Thistle Jayewardene, there are several other leading figures, whose dedication and extraordinary contribution has been responsible for the evolution of Anaesthesia and Critical Care in Sri Lanka to the esteemed standard it holds at present. I do remember them with utmost respect and profound gratitude.

Ladies and gentleman, that was a brief synopsis of the beginnings of Cardiac surgery, Anaesthesia and Critical Care in Sri Lanka. Let me now speak a few words, on the present status of Cardiac Anaesthesia and Critical Care, nearly half a century later.

\section{The present........}

Cardiac surgical services have since expanded significantly and today there are four government hospitals in addition to the National Hospital of Sri Lanka, performing cardiac surgery.
Private sector also has contributed to the expansion of cardiac surgical facilities in Sri Lanka. At present there are four private hospitals, all in Colombo, with functioning cardiac units with Nawaloka Hospital being the first private hospital to initiate a fully equipped cardiac surgical service.

Now I would like to take you into the cardio thoracic operating theatre of the NHSL, on a normal working day;

Once the patient is scheduled for surgery, the team of Anaesthesiologists need to ensure that the patient is evaluated, risk stratified, optimized, reassured and prepared. He is then anaesthetized, monitored with invasive lines we have placed connected to various machines and monitors. The heart monitor bleeps regularly and the ventilator delivers oxygen into his lungs. ..... Then the by-pass machine starts to function, and his life giving blood is drained to an external sterile chamber. The heart and lungs stop functioning. The surgeon gets activated!

When he is done - it's like springtime! The monitors jump back to life and start beeping as the heart slowly begins to beat. Today refinements in hardware, techniques, invasive monitoring and new drugs, ensure vital organ protection, and have made the Anaesthetists life much easier. Once the surgery is over, patient is transferred to the intensive care unit with much vigilance. Inside the cardiac ICU, great care is taken to make this patient stable. Needless to say like the surgery itself, this too is a very delicate operation. A lot of resources and a multitude of personnel are involved during this process. It is ensured, that the patient is relieved from pain and other symptoms, lungs expanded, mobilized and recovered, usually by about the $3^{\text {rd }}$ day.

As you can see, this essentially is a team effort and I would like to pay tribute to all the staff in our unit, who are the unsung heroes in this exercise, without whose dedication and service, it would be quite impossible to provide the standard of care that we extend.

This collective effort has not been without a very positive outcome. According to figures released in July 2010 by the Care Quality Commission, an independent health and social care watchdog in England, in collaboration with the Society of Cardiothoracic Surgery in Great 
Britain and Ireland, survival rates of CABG in the UK during 2008 to 2009 is $98.4 \%$. In the USA it is $97.9 \% .{ }^{6}$ In NHSL the ICU survival rates are $97.22 \%$ for 2010 and $98.75 \%$ for 2011, which I would say is a highly commendable achievement and something we could be extremely proud of.

\section{Looking into the future....}

My dear friends, as we all know, we as a nation are just emerging from a brutal war of three decades, which engulfed our country.

In the past, it was a case of managing day to day affairs and for many there was not much hope for the future. Thousands of lives which could have contributed to the betterment of our beloved motherland were lost due to no fault of theirs. I am sure we can all recall the horrible times, when we were not sure of what will happen on a particular day, when we were supposed to keep beds ready in our ICUs, wards, to accommodate potential victims of a bomb blast or some sort of a terrorist attack. We as a profession cannot say that we were not affected by this utmost calamity. Such unpleasant times are behind us and now we are in a position to live without the burden of the war. Hence, it has provided us with an opportunity to think without being affected, to think beyond borders and seek development.

It is with a sense of pride that I mention at this point, despite all these adversities we faced, our quantitative health indices have consistently remained quite comparable with developed countries. We are a country with excellent health indices, in spite of having a relatively small health budget and low per capita income. A major contributory factor to this is our strong health system and policies, which did not collapse in the face of all these adversities we faced.

With this background, a question which often lingers in my mind is "Have we really achieved our true potential in providing good quality health care, that we as medical professionals are capable of?"

I personally think that we should increase our focus more on the quality of care we provide to our patients. This does not in any way suggest that we provide poor quality care. However, there is always room for improvement, space for development and potential to reach the next level.

In reality, each one of us may be striving to enhance quality on an individual basis. But in this way, we all can agree that the quality of care we administer might depend on each professional. The main draw back in this system is that we are not capable of seeing the broader picture independent of individual cells. It is very encouraging that the Ministry of Health has also identified quality improvement as an area which needs more emphasis. In fact there are Quality Management Units, established in many hospitals under the guidance of the ministry.

However, despite frequent discussion on this topic, do we address it in a systematic and a scientific manner? Thus, I propose the implementation of a systematic approach to maintaining and improving the quality of patient care within our health system.... Which is called, Clinical governance

The term clinical governance became widely used in health care in the United Kingdom following the Bristol heart scandal in 1995, during which interestingly, the Consultant Anesthetist Dr Stephen Bolsin, exposed the high mortality rate for pediatric cardiac surgery, at the Bristol Royal Infirmary. Clinical governance was originally described within the UK National Health Service (NHS), and its most widely cited formal definition, describes it as: "a system through which organizations are accountable for continuously improving the quality while ensuring the safety of their services and safeguarding high standards of care, by creating an environment, in which clinical excellence will flourish." 7

The current dialogue on Patient Safety began in the United States, with a report published by the International Organization of Medicine in year 2000 named 'to err is human - building a safer health system'. There has been a growing concern on the adverse events faced by the patients in hospitals, and consequences of those events. It is generally accepted that 1 in 10 patients treated in hospitals in the USA, face an adverse event during their stay and $10 \%$ of them die as a result. $40-50 \%$ of those who face adverse events in hospitals, ended up with a permanent disability. Even though the initial reports from other countries showed some lower 
figures, which was mainly attributed to underreporting, it is now widely accepted that $10 \%$ of the patients face an adverse event in hospitals. ${ }^{8,9}$ Unfortunately in Sri Lanka, we do not have published data to comprehend the extent of the problem.

It is almost impossible for us to seek absolute improvement in clinical quality, without developing an environment of quality. In this regard, an initial step would be incident or adverse event reporting. This was how it was started in the United States. Dr. Jayantha Jayasuriya, our outgoing President has streamlined a project to report and record adverse events in ICUs and operating theatres in Sri Lanka. We should be thankful and very grateful to him for formulating such a project and aiding us in implementing the initial stage.

I propose and plan during my tenure in office to focus on reducing morbidity and mortality in Anesthesia and Critical Care, and to improve the patient care in Sri Lanka. This will be achieved through a programme of clinical governance.

Towards achieving this goal, I wish to introduce a programme of seven steps.

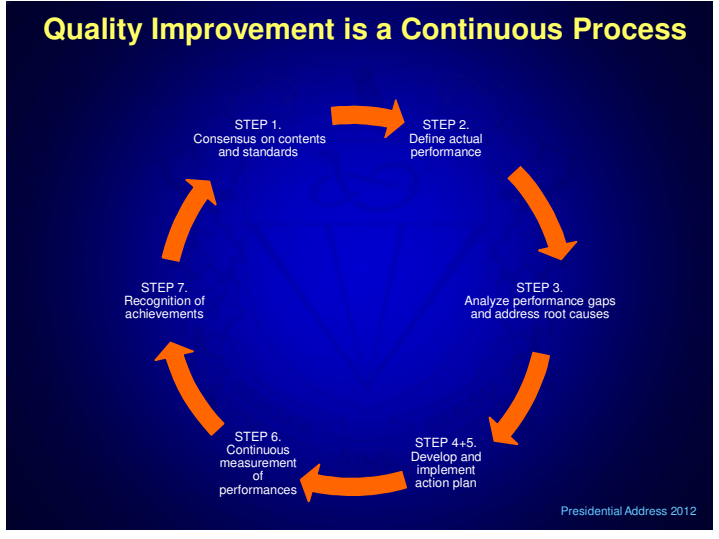

The first step would be for us to get together for a brainstorming session and reach a consensus on the areas that need to be addressed. The initial focus would be on critical care units across Sri Lanka. In this session we need to identify areas which have a high impact on adverse patient outcomes. I would like to take ventilator associated pneumonia as one example, to explain this entire process.

Just to highlight the significance of Ventilator Associated Pneumonia or VAP, I would like to quote figures released by the Center for Disease Control, USA:

a) VAP has been reported to be the most common hospital-acquired infection among patients requiring mechanical ventilation.

b) The mortality rate of patients with VAP is higher than that of uninfected patients $(50 \%$ versus $34 \%$ ).

c) VAP increases a patient's length of stay in the ICU by 6.1 days and hospitalization by 10.5 days.

d) This would significantly impact health care expenditures by adding an estimated 16,000 to 41,000 dollars to the cost of a hospital admission.

In the same brain storming session, we must give clear cut agreed upon definitions for each of the areas that were identified. This will ensure uniformity and prevent confusion. For example Ventilator associated pneumonia is defined by the CDC as a" Nosocomial pneumonia in a patient on mechanical ventilatory support for greater than or equal to 48 hours".

Step 2 of the process, demands us to carry out an assessment of the current ground situation of the identified areas. In order to do so data such as number of admissions to each unit, number of patients with VAP, number of ventilator days and duration of ICU stay need to be collected in a uniform manner at each local unit.

Next we have to analyze the collected data, and provide a feedback, which is confidential to each unit. This is no doubt a challenging task. I am thankful to the ministry of health for extending their support and also acting as a facilitator to obtain international collaboration to develop a database where all tasks related to this program can be carried out. Based on this feedback, each unit should evaluate its performance, at monthly held Morbidity and Mortality conferences.

Once a general overview of the current situation is received, the next step would be to define and implement interventions. As most of us are aware, the Institute for Healthcare Improvement in the USA in 2005 has developed a system of intervention sets, which are termed care bundles. Care bundles, in general, are groupings of best evidenced based practices, with respect to a disease process that individually improve care. When the groupings are applied together, the 
result is substantial improvement in patient care with a superior outcome.

Returning to my initial example of VAP, we all have an idea about the ventilator bundle, which includes;

1). Elevation of the head end of the bed

2). Daily "Sedation Vacations" and assessment of readiness to extubate

3). Peptic ulcer disease prophylaxis

4). Deep Vein Thrombosis prophylaxis

5). Daily oral care with chlorhexidine

As you can see, all these are simple but proven to be very effective interventions. I am sure these bundles must be in practice in some of your units.

Evidence is abundant to see how implementing a simple strategy like this helped to reduce the impact of VAP. For example Resar et al .reported on a study conducted in 2005 in 35 Intensive Care Units in the USA, by using the ventilator care bundle, the incidence of VAP was reduced, by an average of $44.5 \%$ during the 2-year study period. ${ }^{10,11}$

I think you will agree that, continued analysis of data at the central level will help us to determine the outcome of our interventions. Furthermore it will highlight performance gaps and aid us in addressing the root causes for those gaps. Depending on the results, periodic release of upgraded best sets of interventions will be released.

This program should also include an effective way of recognizing and rewarding high performances. Individuals and units that excel should be rewarded accordingly.

In short what I explained was, taking implementation of care bundles to reduce VAP as an example, how a successful clinical governance program should take place. ${ }^{12,13,14}$

As we all can see here, evidence showing positive outcomes, with establishment of such a programme, is so abundant and overwhelming. $15,16,17,18$

As we have experienced, changing an existing culture of a healthcare organization is easier said than done. In a sociological perspective all adults resist change. Realization of resistance to change has to be the key factor one should bear in mind, before embarking on such a complex activity. Winning the confidence and support of all stake holders including the patients is vital. To this end, we will have to ensure all parties are sufficiently educated about this program.

I do understand with the current work load each Consultant Anesthetist is dealing with, additional responsibilities as what I'm proposing looks very daunting. But since this is a program, which has enormous potential benefits to the people of Sri Lanka, I hope all my colleagues seated here will take a lead role in ensuring the continuity of this process.

As I mentioned earlier, we now have the opportunity to serve our beloved mother land with a new vigor, and set an example to others by challenging ourselves to become better at what we are doing. So my dear colleagues, lets join hands together to make this program a success.

\section{References:}

1. Thys DM. Cardiac Anaesthesia: thirty years later--the second annual Arthur E. Weyman lecture, Anesth Analg. 2009 Dec;109(6):178290.

http://dx.doi.org/10.1213/ANE.0b013e3181be4 002 PMid:19923503

2. Kaplan J A, Cardiac Anaesthesia, 5th Edition

3. Grenvik A, Pinsky MR, Evolution of the intensive care unit as a clinical center and critical care medicine as a discipline, Crit Care Clin.2009 Jan;25(1):239-50 .

http://dx.doi.org/10.1016/j.ccc.2008.11.001

PMid:19268805

4. Jayasuriya J, How we got to where we arePresidential address. Sri Lankan Journal of Anaesthesiology,2011,XVIX:5-16

5. Amarasekera S, Twenty Five Years of Service. Journal of the College of Anaesthesiologists of Sri Lanka, 1996, VI, 1-3

6. Care quality commission, July 2010 www.cqc.org.uk

7. Scally G, Donaldson L, Clinical governance and the drive for quality improvement in the new NHS in England, BMJ. 1998 July 4; 317(7150): 61-65. http://dx.doi.org/10.1136/bmj.317.7150.61

PMid:9651278 PMCid:1113460

8. Joint International Commission on Patient 
Safety jcicustomerservice@pbd.com

9. Joint Commission on Accreditation of Healthcare Organisations. Joint Commission adds new patient safety standards. 2 nd January 2001

10. Resar et al. Bundle approach to improve ventilator care processes and reduce ventilatorassociated pneumonia. Jt Comm J Qual Patient Saf 2005; 31(5): 243-248

PMid:15960014

11. Stephen Gilligan, Melanie Walters, (2008) "Quality improvements in hospital flow may lead to a reduction in mortality", Clinical Governance: An International Journal, Vol. 13 Iss: 1 , pp. $26-34$ http://dx.doi.org/10.1108/14777270810850607 12. Barraclough BH. Safety and quality in Australian healthcare: making progress. Med J Aust 2001;174:616-17

PMid:11480678

13. Kiefe CI, Allison JJ, Williams OD, Person SD, Weaver MT, Weissmann NW. Improving quality improvement using achievable benchmarks for physician feedback. A randomized controlled trial. JAMA 2001;285:2871-79

http://dx.doi.org/10.1001/jama.285.22.2871

PMid:11401608

14. Cook R, Render M, Woods DD. Gaps in the continuity of care and progress on patient

safety. BMJ 2000;320:791-94

http://dx.doi.org/10.1136/bmj.320.7237.791

PMid:10720370 PMCid:1117777

15. Barach P, Small SD. Reporting and preventing medical mishaps: lessons from nonmedical near-miss reporting systems. BMJ 2000;320:759-63.

http://dx.doi.org/10.1136/bmj.320.7237.759

PMid:10720361 PMCid:1117768

16. Wright J, Dugdale B, Hammond I, Jarman B, Neary M, Newton D, et al. Learning from death: hospital mortality reduction program. J R Soc Med2006;99:303-8.

http://dx.doi.org/10.1258/jrsm.99.6.303

PMid:16738373 PMCid:1472716

17. Berwick D, Calkins DR, McCannon CJ, Hackbarth AD. The 100000 Lives Campaign: setting a goal and a deadline for improving health care quality. JAMA2006;295:324-7. http://dx.doi.org/10.1001/jama.295.3.324

PMid:16418469
18. Wolff AM, Bourke J, Campbell, IA, Leembruggen DW. Detecting and reducing hospital adverse events: outcomes of the Wimmera clinical risk management program.

Med J Aust 2001;174:621-25

PMid:11480681 